\title{
Corrigendum: Independent and coordinate trafficking of single Drosophila germ plasm mRNAs
}

Shawn C. Little, Kristina S. Sinsimer, Jack J. Lee, Eric F. Wieschaus and Elizabeth R. Gavis

Nat. Cell Biol. 17, 558-568 (2015); published online 6 April 2015; corrected after print 1 February 2016

In the version of this Article originally published, the sentence ' $13 \%$ of GFP-Vas granules contain nos mRNAs and $11 \%$ contain $c y c B$ ' in the caption of Fig. $4 \mathrm{~h}-\mathrm{j}$ was incorrect; it should have read ' $69 \%$ of GFP-Vas granules contain nos and $51 \%$ contain $c y c B$ '. This has been corrected in all online versions of the Article.

\section{Corrigendum: Systematic proteomics of the VCP-UBXD adaptor network identifies a role for UBXN10 in regulating ciliogenesis}

Malavika Raman, Mikhail Sergeev, Maija Garnaas, John R. Lydeard, Edward L. Huttlin, Wolfram Goessling, Jagesh V. Shah and J. Wade Harper

Nat. Cell Biol. 17, 1356-1369 (2015); published online 21 September 2015; corrected after print 1 February 2016

In the version of this Resource originally published, the sequence for the UBXN7 morpholino was reported incorrectly in the Methods section as 5'-TTTTGGATTCTCCACCCGAAGCCAT-3'. The correct sequence is 5'-ATGCGTCTCCGAGAGTCGCCATCTT-3'. This has been corrected in all online versions of the Resource.

\section{Erratum: Actin puts the squeeze on Drosophila glue secretion}

\section{Christien J. Merrifield}

Nat. Cell Biol. 18, 142-144 (2016); published online 28 January 2016; corrected after print 4 February 2016

In the version of this News and Views article originally published, the author's affiliation should have read "Institute for Integrative Biology of the Cell, Bât. 34, Avenue de la Terrasse, 9198 Gif sur Yvette cedex, France”. This has been corrected in all online versions of the News and Views article. 